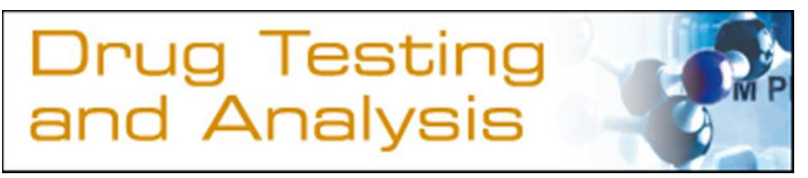

\title{
A review of chemical 'spot' tests: a presumptive illicit drug identification technique
}

\begin{tabular}{|c|c|}
\hline Journal: & Drug Testing and Analysis \\
\hline Manuscript ID & DTA-17-0289.R1 \\
\hline Wiley - Manuscript type: & Review \\
\hline Date Submitted by the Author: & $\mathrm{n} / \mathrm{a}$ \\
\hline Complete List of Authors: & $\begin{array}{l}\text { Philp, Morgan; University of Technology Sydney, Centre for Forensic } \\
\text { Science } \\
\text { Fu, Shanlin; University of Technology Sydney, Centre for Forensic Science }\end{array}$ \\
\hline Keywords: & $\begin{array}{l}\text { presumptive identification, color test, new psychoactive substances, } \\
\text { chemistry }\end{array}$ \\
\hline Abstract: & $\begin{array}{l}\text { Chemical 'spot' tests are a presumptive illicit drug identification technique } \\
\text { commonly used by law enforcement, border security personnel, and } \\
\text { forensic laboratories. The simplicity, low cost and rapid results afforded by } \\
\text { these tests make them particularly attractive for presumptive identification } \\
\text { globally. In this paper, we review the development of these long- } \\
\text { established methods and discuss color test recommendations and } \\
\text { guidelines. A search of the scientific literature revealed the chemical } \\
\text { reactions occurring in many color tests are either not actively investigated } \\
\text { or reported as unknown. Today, color tests face many challenges, from the } \\
\text { appearance of new psychoactive substances to concerns regarding } \\
\text { selectivity, sensitivity, and safety. Advances in technology have seen color } \\
\text { test reagents used in digital image color analysis, solid sensors and } \\
\text { microfluidic devices for illicit drug detection. This review aims to summarize } \\
\text { current research and suggest the future of presumptive color testing. }\end{array}$ \\
\hline
\end{tabular}

\section{SCHOLARONE $^{\text {"x }}$ \\ Manuscripts}




\section{A review of chemical 'spot' tests: a presumptive illicit drug identification technique}

Morgan Philp and Shanlin Fu

Short title: Review of chemical spot tests for illicit drug detection

Chemical 'spot' tests are a presumptive illicit drug identification technique commonly used by law enforcement, border security personnel, and forensic laboratories. The simplicity, low cost and rapid results afforded by these tests make them particularly attractive for presumptive identification globally. In this paper, we review the development of these longestablished methods and discuss color test recommendations and guidelines. A search of the scientific literature revealed the chemical reactions occurring in many color tests are either not actively investigated or reported as unknown. Today, color tests face many challenges, from the appearance of new psychoactive substances to concerns regarding selectivity, sensitivity, and safety. Advances in technology have seen color test reagents used in digital image color analysis, solid sensors and microfluidic devices for illicit drug detection. This review aims to summarize current research and suggest the future of presumptive color testing.

Keywords: color spot test, presumptive identification, illicit drugs, seized material, new psychoactive substances

\section{Introduction}

The large and lucrative illicit drug market continues to grow each year as it adapts to a changing marketplace. On a global scale, the extent of drug supply and demand is indicated by the 2.4 million drug seizures made by law enforcement personnel annually ${ }^{[1]}$. The 2017 World Drug Report by the United Nations Office on Drugs and Crime (UNODC) found the most commonly seized drugs by number were cannabis, amphetamine-type stimulants, opioids and cocaine-related substances, respectively ${ }^{[1]}$. Comparatively, new psychoactive substances (NPS) were seized in much lower quantities. However, the growing number of NPS on the market is significant, with one new drug reported to the EU Early Warning System each week in $2016^{[2]}$. Fentanyl and other synthetic opioid derivatives remain extremely dangerous public safety threats, particularly in the United States where $167 \mathrm{~kg}$ of illicit fentanyl was seized in $2015^{[3]}$. Other seized substances include tryptamines, anesthetics, steroids, benzodiazepines, and hallucinogens, all of which Australia saw record numbers of seizures in the last reported year ${ }^{[4]}$.

Suspected illicit substances seized by police and customs officers at national and state borders are submitted for analysis to identify the drug present. This identification process typically follows a sequence of techniques designed to be cost and time efficient while 
providing reliable results. Qualitative presumptive analysis for drug samples indicates the presence or absence of a particular drug class using simple methods often amenable to portable field test kits. These simple methods are followed by a confirmatory instrumental analysis which uses high discriminating power techniques performed in a laboratory to accurately identify all components, quantify drugs present, and profile chemical impurities ${ }^{[5]}$. The Scientific Working Group for the Analysis of Seized Drugs (SWGDRUG) provide recommendations for the minimum standards of identification of seized drugs and have divided analytical techniques into three categories (A, B, and C) based on their respective discriminating power ${ }^{[6]}$. Low discriminating power techniques (category $\mathrm{C}$ ) include color tests, immunoassays, and ultraviolet spectroscopy, while high discriminating power techniques (category A) include infrared and Raman spectroscopy and mass spectrometry. Forensic laboratories combine techniques such as chromatography (category B) and mass spectrometry to achieve confirmatory analysis of controlled substances, for example, Gas Chromatography-Mass Spectrometry (GC-MS ${ }^{[7]}$.

Despite the low discriminating power, presumptive analysis of controlled substances is critical to investigation processes as it is often the first step in the identification and will determine the next tactical decision, such as search and arrest warrants ${ }^{[8]}$. The most commonly used presumptive screening tool is the color (spot) test used by law enforcement in the field and technicians in a forensic laboratory. Chemical reagents are added to a small sample of the material and the color changes are observed with the naked eye. Specified color changes will indicate the presence of a particular drug. The lack of sample preparation required, ease of use, rapid results afforded, portability, and low cost make chemical color tests an ideal presumptive identification. These attributes are especially useful considering the large numbers of samples received. Concerns regarding the selectivity of color testing are apparent and have received attention via numerous media reports ${ }^{[9,10]}$. In attempts to improve on the subjective nature of the test, colorimetric analysis has been incorporated into chemical color testing ${ }^{[11]}$ showing potential for semi-quantitative analysis ${ }^{[12]}$. The emergence of NPS, often disguised as traditional recreational drugs, led to color test validation studies to determine effectiveness and potential cross-reactivities of current test methods ${ }^{[13]}$.

This review aims to provide an overview of the history and prevalence of color testing before describing the chemical mechanisms of the reactions. Cases reporting false positive results are presented, along with a review of current advances made in this field. Ultimately, this paper seeks to show the benefits and limitations of chemical color testing as a means of presumptive illicit drug identification, and suggest the future of color testing.

\section{Historical overview}

\section{Microchemistry}

Microchemistry began to establish itself in the early nineteenth century as a field of chemistry that required small amounts of material to develop either a change in color, formation of precipitate or evolution of gas with specific compounds. Early discoveries included the blue 
color reaction between starch and iodine ${ }^{[14]}$ and various chemical reactions with poisons ${ }^{[15]}$. In the twentieth century, this field grew significantly as people soon realized the benefit of micromethods over macromethods due to their precision and rapidity ${ }^{[16]}$. A forefather of 'spot testing,' Fritz Feigl, produced important work during this period by introducing new methodologies for characterizing inorganic chemical species using organic reagents to create intensely colored products, and also introducing the concepts of specificity, selectivity, and sensitivity ${ }^{[17-19]}$.

\section{Drugs of abuse testing}

In the $19^{\text {th }}$ century, color and precipitation tests became essential in early forensic toxicology studies for the identification of plant alkaloids. A series of tests named after their chemist inventors appeared in the mid to late 1800s, including Dragendorff, Marquis, Mandelin, Mecke, and Froehde ${ }^{[20]}$.

The discovery of new alkaloids combined with greater knowledge of their chemical structures led to the arrival of new color tests in the following decades, including Chen's test for ephedrine ${ }^{[21]}$ and Scott's test for cocaine ${ }^{[22]}$. The arrival of synthetic drugs of abuse saw further successful applications of these color test methods, and in 1985, Jungreis detailed the necessity of spot testing for drug and poison detection in the growing area of narcotic abuse $^{[23]}$.

Clarke's Analysis of Drugs and Poisons ${ }^{[24]}$, a reference text written by leading international scientists provides a wealth of information to forensic laboratories on methods of identification, including color tests. Recent decades have also seen the publication of government documents detailing drugs of abuse color test standards ${ }^{[25]}$, technical notes on color testing ${ }^{[26]}$, and methods for validating color tests ${ }^{[6,27]}$.

\section{Chemistry of common color tests}

A chemical reaction between the drug of interest and the test reagent(s) causes the observed color change in chemical spot tests. Mechanistically, an electron transfer takes place between the drug molecule (or substructure thereof) and the chemical reagent to produce colored metal complexes and charged organic species. An important aspect that has a considerable effect on the color and intensity of the products is the $\mathrm{pH}$ of the test solution ${ }^{[28]}$. A list of the 15 most commonly used color test reagents and target drug classes is provided in Table 1, while the chart in Figure 1 classifies these color tests based on $\mathrm{pH}$ conditions and products formed. Color tests can also be classified based on the drugs or substructures that react with the reagent. 
These test reagents produce color changes with many drug classes. The Marquis reagent is the most frequently used color test for screening unknown substances and is the first to be performed in test sequences ${ }^{[38]}$. Originally developed for the detection of morphine and other alkaloids via a red-violet color change ${ }^{[39]}$, it has since found excellent use as a general screening test for many synthetic drugs. For example, orange-brown, black and olive-green color changes with amphetamine $\mathrm{HCl}, 3,4$-methylenedioxyamphetamine $\mathrm{HCl}$, and 3,4dimethoxymethamphetamine $\mathrm{HCl}$, respectively ${ }^{[40]}$. However, other compounds have also been found to react with Marquis, including aspirin and sugar ${ }^{[40]}$. In a German report on the chemistry of color tests, $\operatorname{Kovar}^{[26]}$ showed the purple colored product with opium alkaloids is an oxonium-carbenium salt, while amphetamine reacts with only one molecule of formaldehyde to form an orange carbenium ion product (see Figure 2a).

Compared to Marquis, the Liebermann's reagent is mentioned significantly less in the literature. Widdop ${ }^{[30]}$ describes the many colors seen with Liebermann's, while other reports show its use in the detection of methcathinone analogs ${ }^{[41]}$ and synthetic cannabinoids containing an indole structure ${ }^{[42]}$. A critical investigation into the chemical reaction of the Liebermann color test showed the mechanism occurring with phenols ${ }^{[34]}$. The nitrous acid reagent produces carbocations and $\mathrm{N}$-nitrosamines with primary and secondary amines, respectively (see Figure $2 \mathrm{~b}$ ). The substituents present on the benzene ring will affect the color observed, and occasionally it is necessary to heat the test at $100{ }^{\circ} \mathrm{C}$ to see the result ${ }^{[30]}$.

Transition metal complexes are highly colored compounds that change color upon a change in oxidation state and have therefore been found very useful as reagents in color tests. Color tests based on reduction-oxidation reactions often involve transition metals in their highest valence state dissolved in sulfuric acid ${ }^{[43]}$. The ammonium vanadate reagent in the general screening Mandelin's test is present as vanadium(V), reduced to vanadium(IV) in the presence of alkaloid compounds such as cocaine, codeine, and heroin producing orange, olive and brown colors, respectively ${ }^{[44]}$ (see Figure $2 \mathrm{c}$ ). The mechanisms of these reactions with drugs of abuse have not been investigated, and it is unknown if the colored complex ion product contains drug molecules acting as ligands. The molybdic acid reagent in Froehde's test also undergoes a redox reaction with molybdenum(VI) reducing to molybdenum(II) in the presence of aromatic compounds (see Figure 2d). Wongwiechintana et al. ${ }^{[43]}$ used X-ray Diffraction (XRD) to determine the structure of the purple product with morphine and found a ring rearrangement followed by dehydration produced a hydroxyquinone system on the aromatic morphine ring. This work demonstrated the Molybdenum complex was not responsible for the reaction color change.

\section{Functional group selective}

Color tests can react with a certain functional group present in the compound and are therefore appropriate for detection within a range of drug classes. Sodium nitroprusside is a chemical reagent that has previously been described for its ability to detect methyl ketones 
and aldehydes ${ }^{[45]}$. Modification of the test method to include acetaldehyde changed the target class of compounds to secondary amines and thus made the method useful in presumptive testing of many illicit compounds ${ }^{[46]}$, particularly methamphetamine and 3,4methylenedioxymethamphetamine (MDMA). The newly named Simon's test affords a blue colored product as the result of an iron complex, named the Simon-Awe complex ${ }^{[26]}$ (see Figure 3a).

References to the Zimmerman reagent from the 1950s and 1960s relate to the detection of steroidal compounds ${ }^{[47,48]}$ wherein the color development is due to a reaction occurring at the carbonyl and adjacent methylene group. However, in a report from the UNODC, the Zimmerman reagent was recommended for synthetic cathinone detection ${ }^{[37]}$. $\operatorname{Kovar}^{[26]}$ also describes the use of this reagent for benzodiazepine detection through the creation of a Meisenheimer complex (see Figure 3b).

A simple functional group identification test for the presence of phenols is the ferric chloride reagent. The structure of the resulting purple colored product is due to the iron(III)-phenol complex (see Figure 3c). The importance of the acidity of the test solution ${ }^{[49]}$, as well as solvent and added base ${ }^{[50]}$, has been described. The colored reaction with a cutting agent, baking soda, has also been reported ${ }^{[33]}$.

\section{Drug class selective}

Many color tests are highly specific toward a certain drug class or group based on molecular structure and functional groups present. The Duquenois-Levine (D-L) test for cannabis requires the formation of a purple product and the transfer of that product into the chloroform layer for a positive result ${ }^{[28]}$. Many researchers have reported the exact mechanism occurring as unknown ${ }^{[51]}$. However, more recently, Liquid Chromatography-Triple Quadrupole Mass Spectrometry (LC-MS/MS) and Atmospheric Pressure Ionization-High Resolution Time-ofFlight Mass Spectrometry (API-HRTOFMS) were used to ascertain the chromophore structure $^{[52]}$ (see Figure 4a). Rubiano et al. ${ }^{[53]}$ also looked into detail at the D-L reaction to provide a better understanding of the mechanism. He found that activating substituents on the benzene ring resulted in positive color changes. The targeted drug class for D-L can be ambiguous as to which cannabinoids are detected, with the literature describing its use for cannabis only ${ }^{[30,54,55]}$ and marijuana and hashish, inclusively ${ }^{[42]}$.

Opium alkaloids will react with the Mecke reagent via rearrangement and oxidation in the presence of selenious acid ${ }^{[26]}$ (see Figure $4 \mathrm{~b}$ ). Despite the toxic and corrosive nature of these reagents, they are still frequently employed and more recently show value in distinguishing heroin from fentanyl ${ }^{[56]}$.

The cobalt thiocyanate test for cocaine is one of the less understood test reagents, and its mechanism is not amply described in the literature. Although unable to isolate the colored complex, Oguri et al. ${ }^{[57]}$ proposed an octahedral structure for the cocaine-cobalt(II) thiocyanate complex with two thiocyanate ligands and two bis chelating cocaine ligands, 
based on a stoichiometric study. Another study by Haddoub et al. ${ }^{[36]}$ revisited the use of cobalt thiocyanate for the detection of cocaine by applying the reagent to a TLC plate and proposed a hexacoordinated cobalt(II) complex with one bis chelating cocaine molecule, three water molecules, and one isothiocyanate ligand (see Figure 4c). Scott modified the cobalt thiocyanate test to differentiate between the cocaine free base and cocaine hydrochloride ${ }^{[22]}$.

Cobalt is also present in the Dille Koppanyi reagent for barbiturates which produces a purple cobalt complex, stabilized by isopropylamine molecules ${ }^{[26]}$ (see Figure $4 \mathrm{~d}$ ). The purple color change observed with copper sulfate, and sodium hydroxide solutions as described by Chen and Kao is a test for ephedrine and pseudoephedrine ${ }^{[21]}$. The proposed structure is a copper chelate complex with ephedrine molecules as bidentate ligands, linked via vicinal amino and hydroxyl groups ${ }^{[26]}$ (see Figure $4 \mathrm{e}$ ). Although often described as a test for secondary amines, Toole et al. demonstrated the lack of reaction with secondary amine methcathinone $\operatorname{analogs}^{[41]}$.

Ehrlich's reagent has been used for over 100 years for detection of indoles, specifically those present in lysergic acid (LSD) and other ergot alkaloids. Kovar ${ }^{[26]}$ described the 2:1 ratio of indole to $p$-dimethylaminobenzaldehyde (p-DMAB) in the final colored product (see Figure 4f), however Lamb et al. ${ }^{[58]}$ determined the reaction takes place at the beta position of the indole.

Fast Blue BB salt, 4-Amino-2,5-diethoxybenzanilide diazotated zinc double salt, was described by Watanabe et al. ${ }^{[59]}$ for the determination of cannabinoids in 1979 . The authors found stable diazo compounds were produced with cannabinoids in alkaline media (see Figure 4g). More recently, Dos Santos et al. ${ }^{[60]}$ used UV-Vis, TLC and mass spectrometric methods to evaluate the selectivity of Fast Blue BB salt for cannabinoids in street samples and proved the increased selectivity of FBBBS over FBBS. Dos Santos et al. undertook studies to determine the structure of the products and thus a better understanding of the chemical reaction taking place. FBBS is present in Clarke's as a visualization reagent in Thin Layer Chromatography (TLC) due to the different colors seen with cannabinoids tetrahydrocannabinol, cannabinol, and cannabidiol ${ }^{[61]}$. The principal screening test for cannabis used by Brazilian Forensic Police is a Fast Blue B or BB salt ${ }^{[60]}$.

Zwikker ${ }^{[62]}$ first described the use of an aqueous copper sulfate-pyridine solution for detecting barbiturates in 1931. In efforts to determine the mechanism, Levi and Hubley ${ }^{[63]}$ later detailed the enolized barbituric acid ion interacts with a positively charged copperpyridine complex ion (see Figure 4h).

\section{Current situation}

Today, color tests are strictly used for the presumptive identification of controlled substances only. A recent International Collaborative Exercise (ICE) by the United Nations Office on Drugs and Crime (UNODC) saw 181 laboratories in 67 countries receive four independent 
samples for analysis to monitor drug testing performance globally ${ }^{[64]}$. Color testing was found to be the most commonly employed screening method in these laboratories for the three most recent studies ${ }^{[64-66]}$ (see Figure 5). There are a large number of color spot tests available; however, typically only a handful of these tests are commonly used in the field by law enforcement.

\section{Drug test kits}

Portable drugs of abuse test kits for law enforcement, other agencies, and even individuals are widely available due to a large number of manufacturers and suppliers of these drug test kits. Purchased test kits are ready to be used in the field and come in a range of designs from reagent tubules to pouches to cartridges (see Table 2). In addition to commercial companies, the Laboratory and Scientific Section of the UNODC also develop and produce drug and precursor test kits for law enforcement ${ }^{[67]}$.

An important feature of companies developing drug test kits is their ability to respond to the current illicit drug situation through the development of new test kits or validation of previous kits. The release of a presumptive test specific for fentanyl in 2016 following an outbreak of fentanyl overdose deaths demonstrated this response ${ }^{[76]}$.

The investigation into spot tests for the determination of anabolic steroids revealed Mandelin's reagent accompanied by the sulfuric acid test provided the best indication ${ }^{[77]}$. Commercial companies have been established specifically for the identification of anabolic steroids employing color test reactions that require less than $1 \mathrm{mg}$ of steroid for a visible reaction to occur in typically a few seconds ${ }^{[78,79]}$.

\section{Harm reduction}

In the age of increasing public awareness of drug-facilitated sexual assault, commercial companies developed products suitable for use by those at risk of being drugged. These products are designed to be used discretely in a public club or bar environment. One such test was the "date rape drug detector" coaster that claimed to be able to detect $\gamma$-hydroxybutyric acid (GHB) and ketamine ${ }^{[80]}$. A study by Meyers and Almirall ${ }^{[81]}$ at the time showed this to be true only at high concentrations of the drug in solution, dependent on the beverage matrix, and also stated there are other date rape drugs in circulation that would limit the test's usefulness. Other date-rape drug detection devices that have emerged include beverage containers $^{[82]}$, straws ${ }^{[83]}$, coasters ${ }^{[84]}$, and nail polish $^{[85]}$.

In attempts to reduce harms associated with the use of psychoactive drugs at dance parties, many organizations are providing presumptive color test kits for users to test their drugs. Murray ${ }^{[86]}$ evaluated screening kits for MDMA testing and concluded they should not be used by the public to give a false sense of security as pure and adulterated forms cannot be distinguished. A recent review in the Harm Reduction Journal compared methods of drug 
analysis for suitability in point-of-care services and found color tests to be the best lower technology option due to lower costs, ease of use and rapid results afforded ${ }^{[87]}$. However, the authors ultimately recommend the use of handheld IR or Raman spectroscopy.

\section{New Psychoactive Substances (NPS)}

A review of presumptive color testing would be amiss if the new psychoactive substances (NPS) were not mentioned. Designed to mimic established illicit drugs, the majority of these substances are synthetic cannabinoid receptor agonists, stimulants and classic hallucinogens ${ }^{[8]}$. The application of common presumptive color tests to the new compounds revealed a lack of specificity. Among others, researchers at the University of Wisconsin are conducting research into the development of presumptive tests for these new compounds and have patented a colorimetric assay and $\mathrm{kit}^{[89]}$. The drug detection is based on chemical reactions with multiple dyes and claims to be able to detect a range of drugs, including synthetic cannabinoids, piperazines and synthetic cathinones.

Cuypers et al. ${ }^{[13]}$ performed a comprehensive investigation into the outcomes of five different current color test kits on more than 40 NPS. Cuypers proposed a combination of Marquis, Mecke's and Mandelin's reagents to effectively predict the drug class, with Simon's and Scott's reagents used if identification is not ascertained. This study focused on the phenethylamines, while only four cathinones, five cannabinoids, and two piperazine compounds tested. A similar study by a research group in Korea suggested Marquis, D-L, Zwikker, Mandelin and Liebermann's reagents could distinguish NPS ${ }^{[90]}$.

The emergence of synthetic cannabinoids posed significant problems for their presumptive identification by traditional color tests. Despite being marketed and sold as 'legal high' products, these substances do not contain the active constituent present in marijuana, $\Delta^{9}$ tetrahydrocannabinol (THC) and therefore the D-L test is inappropriate. The synthetic cannabinoids are a diverse class of NPS that contain several different sub-class structures. The ketone functional moiety present in many of the structural subclasses was targeted by Isaacs $^{[91]}$ using the well-known reagent, 2,4-dinitrophenylhydrazine (DNP). The proposed test method included vortexing, removal of the supernatant, the addition of DNP and heating for 5-10 minutes if necessary. The structure of the orange-red precipitates that formed was not characterized, however, categories were established based on their reactivity. It is also worth noting that that the synthetic cathinones failed to react with DNP. Isaacs also demonstrated the Van Urk test was ineffective for analysis of the indole ring present in the 'core' of a synthetic cannabinoid structure due to the net electron deficiency as a result of the ketone substructure strongly withdrawing electrons from the indole ring ${ }^{[91]}$.

A commercially available color test kit has been produced for synthetic cannabinoid presumptive identification. A plastic ampoule containing a reagent and absorbing crystals make up these test kits that are labeled as producing up to six different colors depending on the synthetic cannabinoid present. The specificity of this test is unknown with only 
concentrated sulfuric acid listed as a reagent and test instructions explaining if the test is shaken more than twice, it will become invalid ${ }^{[92]}$.

The second largest group of NPS, the synthetic cathinones, were the subject of the most recent publication from the UNODC aimed at drug testing laboratories. In this recommendation, the Zimmerman reagent is proposed as the most suitable color test for synthetic cathinones. Immediate color changes were seen for 13 of the 16 substances examined, and after 5 minutes, only one cathinone, bupropion, failed to react ${ }^{[37]}$. An earlier study by Toole et al. ${ }^{[41]}$ investigated the suitability of currently available color test methods to synthetic cathinones and found that the Marquis reagent was able to presumptively identify methylenedioxy substituents, while the Liebermann's reagent was best suited to methcathinone analogs, producing intensely yellow colored products. Of the 11 synthetic cathinones studied by Toole, 3-fluoromethcathinone failed to react with Marquis or Liebermann's reagents.

The false-positive results shown by pyrrolidine-type cathinones with the Scott's test for cocaine was resolved by Tsujikawa et al. ${ }^{[93]}$ who suggested employing Chen-Kao's test to differentiate the cathinones, and cocaine based on the colors produced. The results of this study do not agree with the study by Toole et al. ${ }^{[41]}$ that showed cathinone analogs, including one pyrrolidine-type compound, did not react with the Chen-Kao reagent.

Chemical reactions of mephedrone, as an example of a synthetic cathinone, have been studied by research groups for the colored products that result. Parastekar and Barhate ${ }^{[94]}$ showed that oxidation with potassium permanganate in an alkaline solution produces a green color after $10 \mathrm{~min}$, and ferric neocuproine produces a colored complex after boiling for $30 \mathrm{~min}$. Philp et $a l .{ }^{[95]}$ also investigated neocuproine complexes and validated a color test method for synthetic cathinones employing copper-neocuproine. The test requirement of 10 min heating at $80{ }^{\circ} \mathrm{C}$ diminished the applicability of the method. Nycz et al. ${ }^{[96]}$ recently published work on the synthesis of thiocathinones and the nucleophilic addition of aminoguanidine. These studies may prove useful in developing specific color test reactions.

The Marquis and Simon's reagents have been recommended for onsite screening of piperazines despite the faint color changes and low sensitivity ${ }^{[97]}$. In an attempt to find a more specific color test, a limited study looked at the reaction of five piperazine analogs with 1,2naphthoquinone-4-sulfonate (NQS) and validated a successful color test method based on a nucleophilic substitution reaction to afford an orange-red color ${ }^{[98]}$. Chemiluminescent ruthenium complexes with piperazines were described by Waite et al. ${ }^{[99]}$, however the test lacked portability with the requirement for a chemiluminescence detector.

Plant-based NPS, kratom, can be differentiated from marijuana using the D-L test, while other color tests were not especially helpful for its presumptive identification ${ }^{[100]}$. The intensity of the blue colored organic layer of Scott's test following the addition of extra chloroform was shown to distinguish crack cocaine from tryptamine substance, 5-methoxyN,N-diisopropyltryptamione (5-MeO-DIPT, foxy ${ }^{[101]}$. 
Alkaline gold bromide was investigated as a potential color test reagent for ketamine after it produced a deep purple color within one minute of interaction and showed no cross-reactivity with compounds often mixed with ketamine ${ }^{[102]}$. The results also showed that the test reacted with ascorbic acid, mannitol, sucrose, and lactose, however, the color development over time could be used to distinguish these. Ketamine $\mathrm{HCl}$ was also the target analyte in a novel colorimetric kit that produced a purple precipitate with a cobalt complex immobilized onto a nano- $\mathrm{SiO}_{2}$ support ${ }^{[103]}$.

\section{Limitations}

Practitioners are required to have knowledge of the theory and principles behind color testing, including limitations of the tests ${ }^{[104]}$. An interesting article published in the New York Times Magazine titled, How a \$2 Roadside Drug Test Sent Innocent People to Jail, questioned the selectivity of color tests. The authors make an example of the failings of chemical color tests as used by police personnel through the examination of a wrongful conviction due to a false positive result from a presumptive field color test for cocaine ${ }^{[10]}$. Online tabloid newspaper articles have published similar individual accounts describing arrests made based on false positive presumptive color tests for drugs with everyday items such as Krispy Kreme crumbs $^{[105]}$, baking soda ${ }^{[106]}$ and Epsom salts ${ }^{[107]}$.

This is not the first time color testing has been seen in negative light. In 2008 the Marijuana Policy Project funded an investigation into drug testing aimed at police, prosecutors, and judges which resulted in a 40-page report. Case studies detailing Americans that were wrongfully prosecuted and incarcerated based on false positive test results were presented ${ }^{[108]}$. Tsumura et al. ${ }^{[101]}$ showed Scott's test produced false positives with cutting agents including dibucaine and ketamine when using a test sample of more than one milligram. Presumptive test results may also be affected by the presence of more than one drug or the use of coloring agents usually seen in tablets such as ecstasy and piperazines ${ }^{[109]}$.

The limitation of color testing was highlighted in a recent case that saw the seizure of unknown heart shaped tablets in Italy which were presumptively identified as amphetamines using the Marquis reagent. However, confirmatory analysis revealed the tablets contained two anabolic androgen steroids (AAS), methanedione and methyltestosterone, and no trace of amphetamine-type substances ${ }^{[110]}$.

The act of performing color testing in the field also presents problems for those handling the evidence. Extremely potent substances encountered in casework are a threat to law enforcement personnel performing color tests, as minute amounts are lethal and can be inadvertently inhaled or absorbed through the $\operatorname{skin}^{[3]}$. The handling of color test reagents themselves also poses significant safety concerns as many are toxic or highly corrosive substances. 


\section{Spot test regulation}

The Laboratory and Scientific Section of the UNODC has produced several useful manuals for drug testing laboratories. These manuals provide method recommendations for the identification and analysis of seized materials such as cocaine ${ }^{[11]}$, cannabis ${ }^{[112]}$, amphetamine-type substances (ATS) ${ }^{[13]}$, and most recently, synthetic cathinones ${ }^{[37]}$. Practitioners are referred to UNODC manuals that provide procedures for field testing, interpretation of the results and useful practical notes on each test ${ }^{[54]}$.

The development of any scientific method is necessarily accompanied by a thorough and transparent method validation to justify it is fit for purpose. Several groups provide recommendations for such validations. SWGDRUG recommends minimum standards for the forensic examination of seized drugs and includes requirements for method validation studies $^{[6]}$. Color test reagents and kits have also been standardized by the National Institute of Justice (NIJ) ${ }^{[25]}$. The validation parameters pertinent to color tests are selectivity (and specificity), limit of detection (LOD), precision and stability.

\section{Method validation guidelines}

\section{Selectivity (and specificity)}

The selectivity of a color test toward its target drug class is of paramount importance for method validation. The number of test samples used in this validation should be as broad as possible and include all controlled drugs of interest and their precursors, common diluents and excipients, other controlled drugs and real or simulated seized material samples ${ }^{[27]}$. For the method to be accepted, there must not be any significant interference from commonly occurring substances.

Independent researchers, companies, and government organizations have published the results of commercially available test kits and commonly used lab reagents against a range of NPS ${ }^{[13,90]}$, controlled substances and white powder cutting agents ${ }^{[11,108,114]}$ in attempts to reveal and report any false positive or negative responses. Philp et al. demonstrate the importance of selectivity studies to newly developed presumptive tests for piperazines ${ }^{[98]}$ and synthetic cathinones ${ }^{[55]}$. Experimental studies on 42 non-marijuana substances with two commercial test kits showed patchouli, spearmint, and eucalyptus all tested positive for marijuana; while lavender, cypress, and oregano gave inconclusive results ${ }^{[108,115]}$.

An excellent example of a color test adapting to increase its specificity is that of Scott's test for cocaine. The originally developed cobalt thiocyanate was susceptible to many false positives and was modified in 1973 by Scott to make it more specific to cocaine. In 1986 Fansello and Higgins ${ }^{[116]}$ further developed the test to make it more applicable to the cocaine free base as well as the cocaine hydrochloride salt. An attempt to simplify this method, increase sensitivity and remove cross-reactivity with lidocaine saw glycerol replaced with other polyhydroxy alcohols and a polyether or silicon derivative of a polyether ${ }^{[117]}$. Recent 
studies by Tsujikawa et al. ${ }^{[93]}$ have shown the specificity of Scott's test is further improved by the addition of a filtration step.

\section{Limit of detection}

The qualitative nature of the color spot test often leaves the limit of detection (LOD) neglected in presumptive test studies. Serial dilutions of a pure sample are analyzed until the lowest concentration tests positive in five replicates. This concentration is then multiplied by ten and recorded as the 'operational drug detection limit ${ }^{\text {'27] }}$.

Spot tests have been described as sensitive and specific qualitative analyses. However, few studies have focused on the limit of detection and the factors that may affect this detection cut-off. O'Neal ${ }^{[33]}$ determined the detection limits of 36 combinations of test reagent and illicit drug and showed they were very sensitive, with typical LOD's between 1 and $50 \mu \mathrm{g}$. He was also able to show that different color tests able to detect the same drug had significantly different LOD values. For example, the detection of $d$-methamphetamine $\mathrm{HCl}$ had a drug detection limit of $100 \mu \mathrm{g}$ with the Mandelin's reagent and only $10 \mu \mathrm{g}$ with Simon's reagent. LOD is of particular importance to substances with high potency and therefore low dosages, such as LSD which produces hallucinogenic effects after $25 \mu \mathrm{g}$ $\operatorname{doses}^{[118]}$.

\section{Precision}

The legal implications of color tests place significant importance on the results being precise. An analysis of at least ten replicate samples should give no more than $20 \%$ false negative results under repeatability and reproducibility conditions ${ }^{[27]}$. The application of color test kits in the field requires their performance to be particularly robust by not being susceptible to small changes that may occur during routine analysis. It has a been found that the ambient temperature when performing Scott's test affects the resulting color change due to an excellent example of Le Chatelier's Principle ${ }^{[119]}$. At much cooler temperatures, the sensitivity of the test is doubled compared to room temperature, while temperatures above 40 ${ }^{\circ} \mathrm{C}$ decreased the sensitivity two-fold. Velapoldi ${ }^{[38]}$ found that performing color tests at $3{ }^{\circ} \mathrm{C}$ slowed many color test reactions down significantly. In particular, the Duquenois-Levine test was five times slower. Additionally, reactions carried out at higher temperatures showed rapid color changes making transition colors difficult to observe.

\section{Stability}

The stability of the chemical reagents must be considered. Test reagents requiring fresh preparation and refrigeration when not in use are not suitable for field testing purposes, but 
may still be useful in drug testing laboratories. Reagent stabilities are widely published and typically require fresh preparation after one month ${ }^{[25]}$. Velapoldi ${ }^{[38]}$ performed stability studies on test reagents by storing them in $40{ }^{\circ} \mathrm{C}$ water baths and found they remained stable after ten weeks in these conditions.

\section{Advances in color testing}

The chemical color tests in place today have been used without modifications for decades owing to their simplistic and rapid nature. The increased portability of technology and understanding of chemical reactions taking place in color tests have led to advancements in this field.

\section{Digital image analysis}

The color result reported in spot test analysis is a subjective result dependent on the vision of the user and the lighting conditions where the test is performed. Color reference charts such as Munsell and Centroid are often used to limit this potential subjectivity. However, digital image analysis offers a significantly more objective result without changing the color spot test method. Information is extracted from digital images and processed by a computer to produce the red, green, blue (RGB) components of the full image for a given color spot test. Colorimetric analysis products include physical devices such as the Cube ${ }^{[120]}$, used to accurately capture the color of a particular surface, to mobile applications such as ColorAssist ${ }^{[121]}$ that employ a device's built-in camera and allow the user to 'point and shoot' at a particular surface to read the RGB values.

Choodum et al. were the first to apply digital image analysis to the colored products of presumptive color tests for methamphetamine and amphetamine products ${ }^{[12]}$ and opiates ${ }^{[122]}$ by obtaining RGB values of reactions of Marquis and Simon's reagents, and Marquis and nitric acid reagents, respectively. The results, collected from Adobe Photoshop software, were shown to be semi-quantitative and in good agreement with gas chromatographic data. The group later used the built-in camera of a mobile phone, a mobile application, and a custom built color detection box to eliminate lighting interferences in their analysis of seized 'Yaba' in Thailand ${ }^{[123]}$. Importantly, for Amphetamine-type substances (ATS), they were able to demonstrate the ability to subtract a blank color from the product color if the seized samples are colored themselves.

In one study, the performance of Scott's test was evaluated on cut cocaine samples using multivariate image analysis ${ }^{[124]}$. Principle Component Analysis (PCA) was able to distinguish true negative and true positive samples clearly, and interestingly as the sample weight increased, the false positive results also increased.

Elkins et al. ${ }^{[11]}$ compiled a library database of RGB values for color test results using two mobile applications to make presumptive color testing more objective. A total of 27 color 
tests were used on 39 controlled substances and cutting agents which resulted in over 800 drug-test pairs. The result for forensic laboratories is a significant decrease in the time spent performing the tests and recording the results.

\section{Other colorimetric methods}

In 2010, DETECHIP ${ }^{\circledR}$ was described as a novel sensor for drugs of abuse, employing colorimetric and fluorimetric assays suitable for lab and field use. Different to other spot tests, molecular interactions between the drug of interest and non-toxic dyes produce the observed color change. The sensor records twenty responses in a single test by using five dyes, two buffer systems and two methods of analysis. The 20-digit identification code produced was able to identify nine illicit drugs from 11 over-the-counter drugs or cutting agents ${ }^{[125]}$. Significant sample preparation is required, along with the use of a

spectrophotometer and plate reader. Lyons et al. ${ }^{[126]}$ showed that image analysis could be performed to successfully detect and identify a range of illicit materials using the DETECHIP colorimetric sensor, a camera, and a flatbed scanner.

The inability of current commercial tests to detect $\gamma$-hydroxybutyric acid (GHB) at the low levels capable of causing death led Baumes et al. ${ }^{[127]}$ to propose a colorimetric sensor array able to detect GHB at sub-millimolar concentrations with the naked eye. The color changes were based on supramolecular host-guest complexes of fluorescent dyes with organic capsules and even distinguished GHB from $\gamma$-butyrolactone (GBL).

Researchers at the University of Central Florida are identifying drugs based on luminescence that appears when the substances react with certain metal classes and have created a low-cost portable handheld spectrometer with promising results ${ }^{[128]}$.

Recently, the first portable upconversion nanoparticle (UCNP) based sensor device for field testing of cocaine was developed in China ${ }^{[129]}$. Aptamer fragments target cocaine which causes quenching of UCNP luminescence and signals the detection of cocaine. This sensing device is suitable for on-site screening of blood, saliva, and aqueous solutions, despite requiring near infrared (NIR) excitation.

\section{Microfluidic devices}

Microfluidic devices have been applied to four controlled substances to reduce waste, reagent volumes and amount of sample required compared to color testing ${ }^{[130]}$. A significantly cheaper alternative has seen paper-based microfluidic devices become popular. Musile et $a l .{ }^{[131]}$ analyzed seized drugs using paper-based microfluidic devices that employed common color test reagents. Nine psychotropic substances were detected, with results occurring in five 
minutes or less. The authors explain that reagents using concentrated sulfuric acid (Marquis and Mandelin), as well as highly volatile reagents are unable to be employed.

Rotation-driven microfluidic (RDM) devices have also been applied to illicit drug seizures and successfully identified 30 unknown samples. This "lab-on-a-disc" device can control rotation speed, direction and time to produce an objective detection method. Authors state this device will be ideal to replace standard colorimetric test kits that require separate test kits for each test ${ }^{[132]}$.

\section{Solid sensors}

The most recent developments have seen the incorporation of wet chemical color test reagents into different sensor devices. Choodum et al. ${ }^{[133]}$ continued their work on presumptive detection of methamphetamine through the creation of a sol-gel colorimetric sensor that contained Simon's reagents trapped within the polymeric network of the sol-gel matrix. This sensor was incorporated into a tube for in-tube detection, affording quantitative results when combined with digital colorimetry even when performed on colored drug samples and spiked urine samples. Similarly, a solid colorimetric sensor has been developed for the analysis of four amphetamine-type samples by embedding the reagent, 1,2naphthoquinone-4-sulphonate (NQS), into a polymeric matrix ${ }^{[134]}$. A color change is observed following placement of the solid sensor in a buffer solution of the amphetamine samples for 10 minutes. This group is also looking into incorporating cobalt thiocyanate into a matrix for detection of cocaine. The use of solid reagents has been shown to overcome inherent disadvantages of liquid reagents, such as stability.

\section{Conclusions and future perspectives}

The successful use of chemical color test methods developed in previous decades and centuries thus far has been due to their simple, rapid and portable qualities. Historically, these microchemical methods offered the best solution for rapid drug identification; however, in more recent years, serious concerns regarding the use of such tests have been raised. The emergence of over 600 new psychoactive substances put significant pressure onto existing color tests to be able to detect and differentiate. This shortfall came at a time when color tests had attracted wide attention and comment regarding false positive results with real implications in casework. A common misnomer is that color tests provide binary outcomes and are easy to interpret. It is important for technicians and officers to be made aware of potential false positives and factors affecting test results.

Advances in technology have led to changes in three key areas surrounding color testing: the objective analysis of results, the incorporation of the test reagents into a more stable form, and the development of devices capable of multiplexing. Advances in nanotechnology have also provided new methods for reporting the presence of illicit drugs based on luminescence. One thing these methods do not change is the requirement for an officer to physically sample the suspect material, a real safety concern. 
Improvements to current methods would likely see further development of sensor devices that can selectively recognize the drug molecule and report the detection with a visual cue, not based on chemical reactions. These chemosensors and biosensors will provide greater selectivity and specificity with the potential for targeting multiple analytes in one test, thus removing the need to perform a battery of tests.

The future of color testing can also refer to the existence of such methods at all. As developments in color testing are made, so too are improvements in the confirmatory analysis to produce devices with increased portability and ease of use. Portable handheld spectroscopic devices with high discriminating power are rapidly becoming popular for forensic drug detection, as they address many limitations of chemical color testing, such as low discriminating power, handling of potentially dangerous substances, and using harsh, toxic chemicals. However, cost-effectiveness is a key metric in the development of a portable field testing device and will need to be maintained to make it available to the developing world.

The presumptive identification of illicit drugs is a crucial component of forensic drug testing that provides rapid information at points of seizure. In countries with limited resources, color testing is used to screen all submitted samples, and its low cost will outweigh the benefits provided by replacing them with portable devices. Greater knowledge in the capabilities of current chemical color tests will significantly improve its successful use in the field.

\section{References}

[1] United Nations Office on Drugs and Crime (UNODC) in World Drug Report, United Nations publication, Vienna, 2017.

[2] European Monitoring Centre for Drugs and Drug Addiction (EMCDDA) in European Drug Report 2017: Trends and Developments, Luxembourg, 2017.

[3] Drug Enforcement Administration (DEA) in National Drug Threat Assessment Summary, US Department of Justice, USA, 2016.

[4] Australian Criminal Intelligence Commission (ACIC) in Illicit Drug Data Report 2015-2016, Commonwealth of Australia, Canberra, 2017.

[5] M. D. Cole, The Analysis of Controlled Substances, John Wiley \& Sons Ltd., England, 2003.

[6] Scientific Working Group for the Analysis of Seized Drugs (SWGDRUG) in SWGDRUG

Recommendations Version 7.1, United States Department of Justice, USA, 2016.

[7] Drug Chemistry Section in Technical Procedure for Drug Chemistry Analysis, North Carolina Department of Justice (NCDOJ), North Carolina, 2015. 
[8] Controlled Substances Unit in Physical Evidence Handbook, Wisconsin Department of Justice, Wisconsin, 2017.

[9] A. Santo 2015, Jolly ranchers, sage and breath mints, The Marshall Project, New York, viewed July 25 2017, <https://www.themarshallproject.org/2015/04/02/jolly-ranchers-sage-and-breathmints\#.kbnL7duLZ>.

[10] R. Gabrielson and T. Sanders in How a \$2 roadside drug test sends innocent people to jail, The New York Times Company, New York, 2016.

[11] K. M. Elkins, A. C. Weghorst, A. A. Quinn and S. Acharya. Colour quantitation for chemical spot tests for a controlled substances presumptive test database. Drug Test. Anal. 2016, 9, 306-310.

[12] A. Choodum and N. Nic Daeid. Digital image-based colourimetric tests for amphetamine and methylamphetamine. Drug Test. Anal. 2011, 3, 277-282.

[13] E. Cuypers, A. J. Bonneure and J. Tytgat. The use of presumptive color tests for new psychoactive substances. Drug Test. Anal. 2016, 8, 136-140.

[14] N. N. Greenwood and A. Earnshaw in The halogens: Fluorine, chlorine, bromine, iodine and astatine, Elsevier, University of Leeds, U.K. , 1997.

[15] T. G. Wormley, Micro-chemistry of poisons, including their physiological, pathological, and legal relations; with an appendix on the detection and microscopic discrimination of blood: adapted to the use of the medical jurist, physician, and general chemist, J.B. Lippincott Company, Philadelphia, 1885.

[16] Strebinger. Vorwort. Mikrochemie 1923, 1, I-IV.

[17] A. Bondi. Editorial. Isr. J. Chem. 1966, 4, 166-168.

[18] F. Feigl and V. Anger, Spot tests in inorganic analysis, Elsevier Science B.V., Amsterdam, 1972.

[19] F. Feigl and V. Anger, Spot tests in organic analysis, Elsevier Science B.V., Amsterdam, 1966.

[20] S. Bell, Crime and circumstance: Investigating the history of forensic science, Praeger Publishers, Westport, 2008.

[21] K. K. Chen. The $\mathrm{CuSO}_{4}-\mathrm{NaOH}$ test of ephedrine isomers and related compounds. J. Am. Pharmaceut. Assoc. 1929, 18, 110-116. 
[22] L. Scott. Specific field test for cocaine. Microgram 1973, 6, 179-181.

[23] E. Jungreis, Spot test analysis: Clinical, environmental, forensic, and geochemical applications, Wiley, 1985.

[24] A. C. Moffat, M. D. Osselton, B. Widdop and J. Watts, Clarke's analysis of drugs and poisons, Pharmaceutical Press, London, 2011.

[25] National Institute of Standards and Technology (NIST) in Color test reagents/kits for preliminary identification of drugs of abuse, National Institute of Justice (NIJ), USA, 2000.

[26] K.-A. Kovar and M. Laudszun in Chemistry and reaction mechanisms of rapid tests for drugs of abuse and precursors chemicals, Pharmazeutisches Institut der Universitat Tubingen, Federal Republic of Germany, 1989.

[27] United Nations Office on Drugs and Crime (UNODC), Guidance for the validation of analytical methodology and calibration of equipment used for testing of illicit drugs in seized materials and biological specimens, United Nations, New York, 2009.

[28] J. I. Khan, T. J. Kennedy and D. R. Christian in Chemical Screening, Humana Press, Totowa, NJ, 2012, pp. 79-90.

[29] United Nations International Drug Control Programme in Rapid testing methods of drugs of abuse, New York, 1994.

[30] B. Widdop in Colour Tests, Eds.: A. C. Moffat, M. D. Osselton, B. Widdop and J Watts, Pharmaceutical Press, London, U.K., 2011.

[31] D. E. Forrester, The Duquenois color test for marijuana: Spectroscopic and chemical studies, Georgetown University, 1997.

[32] B. Widdop in Reagents, Eds.: A. C. Moffat, M. D. Osselton, B. Widdop and J Watts, Pharmaceutical Press, London, U.K., 2011.

[33] C. L. O'Neal, D. J. Crouch and A. A. Fatah in Validation of Twelve Chemical Spot Tests for the Detection of Drugs of Abuse, Eds.: J. A. Siegel, P. J. Saukko and M. M. Houck, Academic Press, Waltham, 2013, pp. 380-387.

[34] M. Fraenkl, D. Svobodová and J. Gasparič. A critical investigation of the liebermann colour test: The formation and behaviour of phenolindophenol in strong acid media. Microchimica Acta 1986, 90, 367-386. 
[35] D. L. Pavia, Introduction to organic laboratory techniques: A small scale approach, Thomson Brooks/Cole, 2005.

[36] R. Haddoub, D. Ferry, P. Marsal and O. Siri. Cobalt thiocyanate reagent revisited for cocaine identification on TLC. New J. Chem. 2011, 35, 1351-1354.

[37] United Nations Office on Drugs and Crime (UNODC) in Recommended methods for the identification and analysis of synthetic cathinones in seized materials, United Nations, New York, 2015.

[38] R. A. Velapoldi and S. A. Wicks. The use of chemical spot tests kits for the presumptive identification of narcotics and drugs of abuse. J. Forensic Sci. 1974, 19.

[39] E. Marquis in Über den Verbleib des Morphin im tierischen Organismus, Kaiserlichen Universitat, Jurjew (Dorpat), 1896.

[40] C. L. O'Neal, D. J. Crouch and A. A. Fatah. Validation of twelve chemical spot tests for the detection of drugs of abuse. Forensic Sci. Int. 2000, 109, 189-201.

[41] K. E. Toole, S. Fu, R. Shimmon, N. Krayem and S. Taflaga in Color tests for the preliminary identification of methcathinone and analogues of methcathinone, 2012, pp. 27-32.

[42] Drug Chemistry Section in Technical Procedure for Preliminary Color Tests, North Carolina Department of Justice (NCDOJ), North Carolina, 2014.

[43] C. Wongwiechintana, E. M. Holt and N. Purdie. Structural identification of a purple product $(5,6-$ dihydro-10-hydroxy-6-methyl-4H-dibenzoquinoline-8,11-dione) of the reaction of Froehde reagent and morphine. Acta Crystallographica Section C 1986, 42, 685-687.

[44] D. E. Newton, Forensic Chemistry, Facts On File Inc, New York, 2007.

[45] B. von Bittó. Ueber die Anwendung des Nitroprussidnatriums als Reagens auf Aldehyde und Ketone. Fresenius Z. Anal. Chem. 1893, 32, 347-351.

[46] K. W. Loach and M. Carvalho. A modified Simon-Lewin reaction: N-nitrosamines as intermediates in the reaction of secondary amines with nitroprusside and acetaldehyde. Anal. Lett. 1973, 6, 25-29.

[47] W. M. Allen, S. J. Hayward and A. Pinto. A color test for dehydroisoandrosterone and closely related steroids, of use in the diagnosis of adrenocortical tumors. J. Clin. Endocrinol. 1950, 10, 54-70.

[48] E. Epstein. An aqueous Zimmermann reagent for the determination of 17-ketosteroids. Clin. Chim. Acta 1962, 7, 735-737. 
[49] T. Hasegawa and T. Usui. Cautionary note regarding the phenol color test by ferric chloride in acidic solution. J. Chem. Educ. 1992, 69, 840.

[50] S. Soloway and S. H. Wilen. Improved ferric chloride test for phenols. Anal. Chem. 1952, 24, 979-983.

[51] D. Christian in Forensic Chemistry/Controlled Substances, Eds.: A. Mozayani and C. Noziglia, Humana Press, 2011, pp. 51-103.

[52] A. D. Jacobs and R. R. Steiner. Detection of the Duquenois-Levine chromophore in a marijuana sample. Forensic Sci. Int. 2014, 239, 1-5.

[53] C. Rubiano, J. Firmin and S. Coticone. The effect of benzene ring substituents on the mechanism of Duquenois Levine (DL) test for cannabinoid detection. J. Chem. Pharm. Res 2014, 6, 1261-1264.

[54] United Nations Office on Drugs and Crime (UNODC) in Rapid testing methods of drugs of abuse, United Nations, New York, 1994.

[55] B. Levine and S. W. Lewis in Presumptive Chemical Tests, Eds.: J. A. Siegel, P. J. Saukko and M. M. Houck, Academic Press, Waltham, 2013, pp. 616-620.

[56] Idaho State Police in Forensic Laboratory Training Manual, Idaho, 2011.

[57] K. Oguri, S. Wada, S. Eto and H. Yamada. Specificity and mechanism of the color reaction of cocaine with cobaltous thiocyanate. J. Hyg. Chem. (Japan) 1995, 41, 274-279.

[58] A. C. Lamb, R. A. Federico-Perez and Z.-L. Xue. Product in indole detection by Ehrlich's reagent. Anal. Biochem. 2015, 484, 21-23.

[59] K. Watanabe, E. Yamaki, I. Yamamoto and H. Yoshimura. A colorimetric method for the determination of cannabinoids with fast blue BB salt. J. Hyg. Chem. (Japan) 1979, 25, 321-326.

[60] N. A. dos Santos, L. M. Souza, E. Domingos, H. S. França, V. Lacerda Jr, A. Beatriz, B. G. Vaz, R. R. T. Rodrigues, V. V. Carvalho, B. B. Merlo, R. M. Kuster and W. Romão. Evaluating the selectivity of colorimetric test (Fast Blue BB salt) for the cannabinoids identification in marijuana street samples by UV-Vis, TLC, ESI(+)FT-ICR MS and ESI(+)MS/MS. Forensic Chem. 2016, 1, 1321.

[61] A. C. Moffat, M. D. Osselton, B. Widdop and J. Watts in Thin-Layer Chromatography, Vol. 1 Pharmaceutical Press, London, UK, 2011

[62] J. Zwikker. Het aantonen en het afzonderen van barbitalen bij het toxicologisch onderzoek. Pharm. Weekbl 1931, 68, 975. 
[63] L. Levi and C. E. Hubley. Detection and identification of clinically important barbiturates. Anal. Chem. 1956, 28, 1591-1605.

[64] International Collaborative Exercises (ICE) in Summary Report Seized Materials, UNODC, Vienna, 2016.

[65] International Collaborative Exercises (ICE) in Summary Report Seized Materials, UNODC, Vienna, 2014.

[66] International Collaborative Exercises (ICE) in Summary Report Seized Materials, UNODC, Vienna, 2015.

[67] Laboratory and Scientific Section 2017, Drug and Precursor Identification Kits, UNODC, Vienna, viewed January 10 2017, <https://www.unodc.org/unodc/en/scientists/druge-kits-new.html>.

[68] 2016, NARK Presumptive Drug Analysis, Sirchie, North Carolina, USA, viewed November 22 2016, <http://www.sirchie.com/products/nark-presumptive-drug-analysis.html $>$.

[69] 2016, Narcotic testing supplies and equipment store, MMC International BV, Breda, The Netherlands, viewed November 22 2016, <http://shop.narcotictests.com/products/narcotic-fieldtests/>.

[70] 2016, NIK Drug Tests \& Kits, The Safariland Group, Jacksonville, Florida, viewed November 22 2016, <http://www.safariland.com/products/forensics/field-drug-tests/nik-drug-tests-and-kits/>.

[71] 2016, ODV Drug Tests and Kits, The Safariland Group, Jacksonville, Florida, viewed November 22 2016, <http://www.safariland.com/products/forensics/field-drug-tests/odv-drug-tests-and-kits/>.

[72] 2016, Drug testing kits, IDenta Touch\&Know, Jerusalem, Israel, viewed November 22 2016, $<$ http://touchandknowusa.com/products/drug-testing-kits>.

[73] 2016, Drug Identification Test Kits, TestKitPlus, Canada, viewed November 22 2016, $<$ http://testkitplus.com/product-category/test-kits/drug-identification-test-kits>.

[74] 2016, EZ Test kits, EZ Test, Amsterdam, The Netherlands, viewed November 22 2016, $<$ http://www.eztestwholesale.com/product-category/ez-test-kits/>.

[75] 2016, QuickCheck Narcotic Identification (Drug Test) Kits, Lynn Peavey Company, Lenexa, Kansas, viewed November 15 2016, $<$ https://www.lynnpeavey.com/product_info.php?cPath=33_105\&products_id=947>. 
[76] Sirchie 2017, NARK II Fentanyl Reagent, viewed May 5 2017, $<$ http://www.sirchie.com/nark20033-fentanyl-reagent.html\#.WTiijeuGOUk>.

[77] D. M. Chiong, E. Consuegra-Rodriguez and J. R. Almirall. The analysis and identification of steroids. J. Forensic Sci. 1992, 37, 488-502.

[78] Colorimetrics 2017, What's in Your Gear?, Colorimetrics, LLC, Colorado, USA, viewed February 3 2017, <http://roidtest.com/>.

[79] LabMax 2015, Presumptive test for detection and identification of steroids, LabMax, Ontario, Canada, viewed February 3 2017, <http://www.labmax.ca/instruction.php>.

[80] Drink Safe 2015, Date Rape Test Coaster, Drink Safe Technologies, Tallahassee, Florida, viewed November 23 2016, <http://www.drinksafetech.com/date-rape-test-coaster/>.

[81] J. E. Meyers and J. R. Almirall. A study of the effectiveness of commercially available drink test coasters for the detection of "date rape" drugs in beverages. J. Anal. Toxicol. 2005, 28, 685-688.

[82] M. T. Abramson and J. C. MacDonald in System and method for detection of a contaminated beverage, Drinksavvy Inc., US, 2015.

[83] J. H. C. Wade, D. L. Wade, C. R. Holman and A. Cooke in Diagnostic testing device for potable liquids, Checkmate Organisation Limited, World, 2006.

[84] Francisco Javier Guerra, Brian Glover and J. S. T. Mccafferty in Method for testing a beverage for illicit substances Checkmate Organisation Limited, World, 2003.

[85] R. Legge, T. Hopson, G. Maracas and P. Bechtel in Personal illicit drug detection method, Legge, R; Hopson, T; Maracas, G; Bechtel, P, US, 2007.

[86] R. A. Murray, P. L. Doering, L. A. Boothby, M. L. Merves, R. R. McCusker, C. W. Chronister and B. A. Goldberger. Putting an ecstasy test kit to the test: Harm reduction or harm induction? Pharmacotherapy 2003, 23, 1238-1244.

[87] L. Harper, J. Powell and E. M. Pijl. An overview of forensic drug testing methods and their suitability for harm reduction point-of-care services. Harm Reduct. J. 2017, 14, 52.

[88] United Nations Office on Drugs and Crime (UNODC) in NPS: New Psychoactive Substances, United Nations, 2016.

[89] E. Pirman 2015, Novel colorimetric drug test for emergent illicit drugs, WiSys Technology Foundation, Wisconsin, viewed September 4 2017, <http://www.wisys.org/news-media/joesph-wuchuck-cornett>. 
[90] Y. Jaesuk, Y. Kyung Sik, L. Yong-seop, H. Kyoung moon, C. Hye Jin, S. Jisoon, K. YoungHoon, P. Hye-Kyung, K. and Hyung Soo. A Presumptive Identification of New Psychoactive Substances using Coloring Test. J. Pharm. Soc. Korea 2017, 61, 65-74.

[91] R. C. A. Isaacs. A structure-reactivity relationship driven approach to the identification of a color test protocol for the presumptive indication of synthetic cannabimimetic drugs of abuse. Forensic Sci. Int. 2014, 242, 135-141.

[92] MMC International B.V. 2016, Narcotic Testing Supplies \& Equipment Store, Breda, The Netherlands, viewed November 22 2016, <http://shop.narcotictests.com/products/narcotic-fieldtests/synthetic-cannabinoids-test-k2-spice/details>.

[93] K. Tsujikawa, Y. T. Iwata, H. Segawa, T. Yamamuro, K. Kuwayama, T. Kanamori and H. Inoue. Development of a new field-test procedure for cocaine. Forensic Sci. Int. 2017, 270, 267-274.

[94] V. Parastekar and V. Barhate. Spectrophotometric determination of mephedrone in a bulk form. Int. J. Curr. Pharm. Res. 2015, 7, 51-55.

[95] M. Philp, R. Shimmon, M. Tahtouh and S. Fu. Development and validation of a presumptive color spot test method for the detection of synthetic cathinones in seized illicit materials. Forensic Chem. 2016, 1, 39-50.

[96] J. E. Nycz, T. Pazdziorek, G. Malecki and M. Szala. Identification and derivatization of selected cathinones by spectroscopic studies. Forensic Sci. Int. 2016, 266, 416-426.

[97] H. Inoue, Y. T. Iwata, T. Kanamori, H. Miyaguchi, K. Tsujikawa, K. Kuwayama, H. Tsutsumi, M. Katagi, H. Tsuchihashi and T. Kishi. Analysis of benzylpiperazine-like compounds. Japn. J. Tech. identif. 2004, 9, 165-184.

[98] M. Philp, R. Shimmon, N. Stojanovska, M. Tahtouh and S. Fu. Development and validation of a presumptive colour spot test method for the detection of piperazine analogues in seized illicit materials. Anal. Methods 2013, 5, 5402-5410.

[99] R. J. Waite, G. J. Barbante, N. W. Barnett, E. M. Zammit and P. S. Francis. Chemiluminescence detection of piperazine designer drugs and related compounds using tris $\left(2,2^{\prime}-\right.$ bipyridine)ruthenium(III). Talanta 2013, 116, 1067-1072.

[100] T. M. Scott, J. K. Yeakel and B. K. Logan. Identification of mitragynine and Odesmethyltramadol in kratom and legal high products sold online. Drug Test. Anal. 2014, 6, 959-963.

[101] Y. Tsumura, T. Mitome and S. Kimoto. False positives and false negatives with a cocainespecific field test and modification of test protocol to reduce false decision. Forensic Sci. Int. 2005, $155,158-164$. 
[102] M. Sarwar. A new, highly specific color test for ketamine (Technical note). Microgram, 2006, 4, 24-28.

[103] B. Maddah, V. alimardani and H. moradifard. A simple colorimetric kit for determination of ketamine hydrochloride in water samples. Anal. Methods 2015, 7, 10364-10370.

[104] ENFSI Drugs Working Group in Education and training outline for forensic drug practitioners, European Network of Forensic Science Institutes (ENFSI), Germany, 2015.

[105] A. Harris in He was arrested for meth, but the crumbs in his car were Krispy Kreme doughnut glaze, Miami Herald Media Company, Florida, USA, 2016.

[106] J. lilley in Baking soda confused for cocaine lands innocent couple behind bars, Sinclair Broadcast Group, Inc., Little Rock, AR, 2016.

[107] S. Augenstein in Man jailed for 4 months until test showed 'meth' was just epsom salt, Advantage Business Media, Canada, 2015.

[108] J. Kelly in False positives equal false justice, The Marijuana Policy Project, Washington D.C., USA, 2008.

[109] S. Strano Rossi, S. Odoardi, A. Gregori, G. Peluso, L. Ripani, G. Ortar, G. Serpelloni and F. S. Romolo. An analytical approach to the forensic identification of different classes of new psychoactive substances (NPSs) in seized materials. Rapid Commun. Mass Spectrom. 2014, 28, 1904-1916.

[110] D. Favretto, F. Castagna, S. Maietti, R. Boscolo-Berto and S. D. Ferrara. When color fails: Illicit blue tablets containing anabolic androgen steroids. J. Pharm. Biomed. Anal. 2013, 83, 260-264.

[111] United Nations Office on Drugs and Crime (UNODC) in Recommended methods for the identification and analysis of cocaine in seized materials, United Nations, Vienna, 2012.

[112] United Nations Office on Drugs and Crime (UNODC) in Recommended methods for the identification and analysis of cannabis and cannabis products, United Nations, New York, 2009.

[113] United Nations Office on Drugs and Crime (UNODC) in Recommended methods for the identification and analysis of amphetamine, methamphetamine and their ring-substituted analogues in seized materials, United Nations, New York, 2006.

[114] D. Cosby in Adulterants and interpretive challenges in forensic science: Effects on colorimetric spot tests for presumptive drug identification and adverse side effects in the body, Boston University, 2014. 
[115] J. F. Kelly, K. Addanki and O. Bagasra. The non-specificity of the Duquenois-Levine field test for marijuana Open Forensic Sci. J. 2012, 5, 5.

[116] J. Fasanello and P. Higgins. Modified Scott test for cocaine base or cocaine hydrochloride. Microgram 1986, 19, 137-138.

[117] S. Amisar in Reagent for the identification of cocaine, Erez Forensic Technology Ltd, Israel, 1998.

[118] A. Campbell, The Australian illicit drug guide, Black Incorporated, Melbourne, 2001.

[119] J. W. McGill, C. A. Dixon and D. Ritter. Discovery of an interesting temperature effect on the sensitivity of the cobalt thiocyanate test for cocaine. Microgram 2008, 6 .

[120] Palette 2017, CUBE Portable Color Digitizer, Palette, Fitzroy, Victoria, viewed May 5 2017, $<$ http://palette.com/cube>.

[121] FTLapps Inc in ColorAssist, 2017.

[122] A. Choodum and N. Nic Daeid. Rapid and semi-quantitative presumptive tests for opiate drugs. Talanta 2011, 86, 284-292.

[123] A. Choodum, K. Parabun, N. Klawach, N. Nic Daeid, P. Kanatharana and W. Wongniramaikul. Real time quantitative colourimetric test for methamphetamine detection using digital and mobile phone technology. Forensic Sci. Int. 2014, 235, 8-13.

[124] M. C. A. Marcelo, K. C. Mariotti, R. S. Ortiz, M. F. Ferrão and M. J. Anzanello. Scott test evaluation by multivariate image analysis in cocaine samples. Microchem. J. 2016, 127, 87-93.

[125] R. M. Burks, S. E. Pacquette, M. A. Guericke, M. V. Wilson, D. J. Symonsbergen, K. A. Lucas and A. E. Holmes. DETECHIP ${ }^{\circledR}$ - A sensor for drugs of abuse. J. Forensic Sci. 2010, 55, 723-727.

[126] M. Lyon, M. Wilson, K. Rouhier, D. Symonsbergen, K. Bastola, I. Thapa, A. Holmes, S. Sikich and A. Jackson in Image analysis of DETECHIP® - A molecular sensing array, Vol. 166 Eds.: D. C. Wyld, J. Zizka and D. Nagamalai, Springer Berlin Heidelberg, Berlin, 2012, pp. 145-158.

[127] L. A. Baumes, M. Buaki Sogo, P. Montes-Navajas, A. Corma and H. Garcia. A colorimetric sensor array for the detection of the date-rape drug $\gamma$-hydroxybutyric acid (GHB): A supramolecular approach. Chemistry - A European Journal 2010, 16, 4489-4495.

[128] National Institute of Justice (NIJ) 2016, Improving the reliability of drug tests done by officers, National Institute of Justice, viewed March 20 2017, 
$<$ https://www.nij.gov/topics/forensics/evidence/controlled-substances/Pages/improving-reliability-ofdrug-tests-by-officers.aspx>.

[129] M. He, Z. Li, Y. Ge and Z. Liu. Portable upconversion nanoparticles-based paper device for field testing of drug abuse. Anal. Chem. 2016, 88, 1530-1534.

[130] S. C. Bell and R. D. Hanes. A microfluidic device for presumptive testing of controlled substances. J. Forensic Sci. 2007, 52, 884-888.

[131] G. Musile, L. Wang, J. Bottoms, F. Tagliaro and B. McCord. The development of paper microfluidic devices for presumptive drug detection. Anal. Methods 2015, 7, 8025-8033.

[132] S. T. Krauss, T. P. Remcho, S. M. Lipes, R. Aranda, H. P. Maynard, N. Shukla, J. Li, R. E. Tontarski and J. P. Landers. Objective method for presumptive field-testing of illicit drug possession using centrifugal microdevices and smartphone analysis. Anal. Chem. 2016, 88, 8689-8697.

[133] A. Choodum, P. Kanatharana, W. Wongniramaikul and N. Nic Daeid. A sol-gel colorimetric sensor for methamphetamine detection. Sensors Actuators B: Chem. 2015, 215, 553-560.

[134] A. Argente-García, N. Jornet-Martínez, R. Herráez-Hernández and P. Campíns-Falcó. A solid colorimetric sensor for the analysis of amphetamine-like street samples. Anal. Chim. Acta 2016, 943, 123-130. 
1

2

3

4

5

6

7

8

9

10

11

12

13

14

15

16

17

18

19

20

21

22

23

24

25

26

27

28

29

30

31

32

33

34

35

36

37

38

39

40

41

42

43

44

45

46

47

48

49

50

51

52

53

54

55

56

57

58

59

60

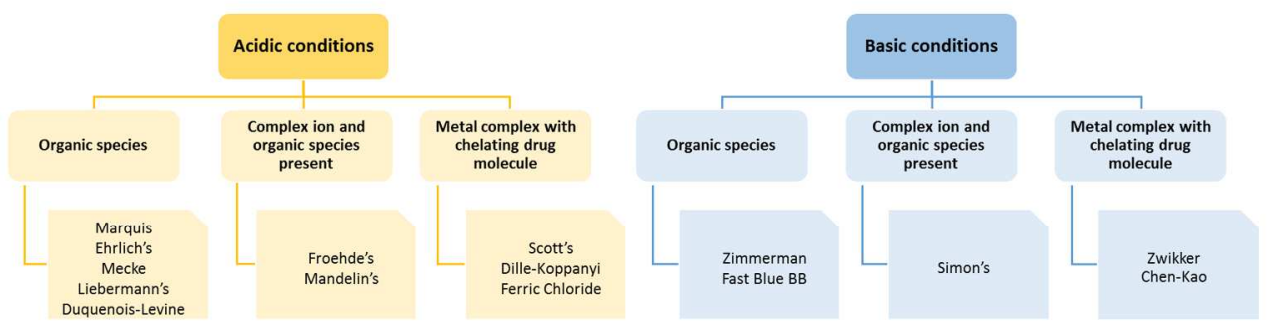

Figure 1. Classification of 15 common color test reagents according to $\mathrm{pH}$ of the test solution and the final colored product formed.

$324 \times 89 m m(150 \times 150 \mathrm{DPI})$

http://mc.manuscriptcentral.com/dta 
(a) Marquis

2 R

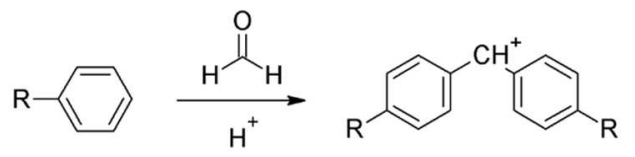

(b) Liebermann's
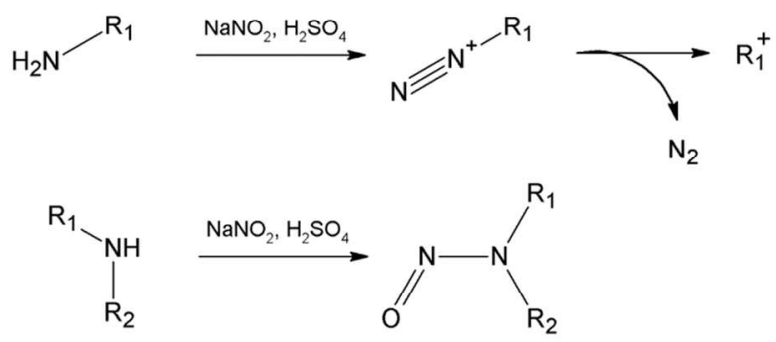

(c) Mandelin's

$$
\mathrm{VO}_{2}^{+}(\mathrm{aq})+\underset{\text { amine/phenol }}{\text { aromatic }} \stackrel{2 \mathrm{H}^{+}}{\longrightarrow} \mathrm{VO}^{2+}(\mathrm{aq})+\mathrm{H}_{2} \mathrm{O}(\mathrm{l})+\underset{\text { oxidized }}{\text { aromatic amine/phenol }}
$$

(d) Froehde's

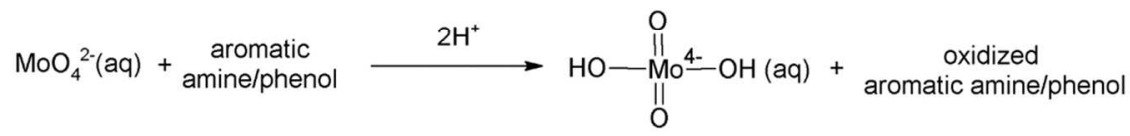

Figure 2. Chemical reactions of common color tests that are selective toward a range of drug classes and used in general screening methods. Marquis reagent (a); Liebermann's reagent (b); Mandelin's reagent (c); and Froehde's reagent (d).

$213 \times 200 \mathrm{~mm}(150 \times 150 \mathrm{DPI})$ 
2

3

4

5

6

7

8

9

10

11

12

13

14

15

16

17

18

19

20

21

22

23

24

25

26

27

28

29

30

31

32

33

34

35

36

37

38

39

40

41

42

43

44

45

46

47

48

49

50

51

52

53

54

55

56

57

58

59

60

(a) Simon's

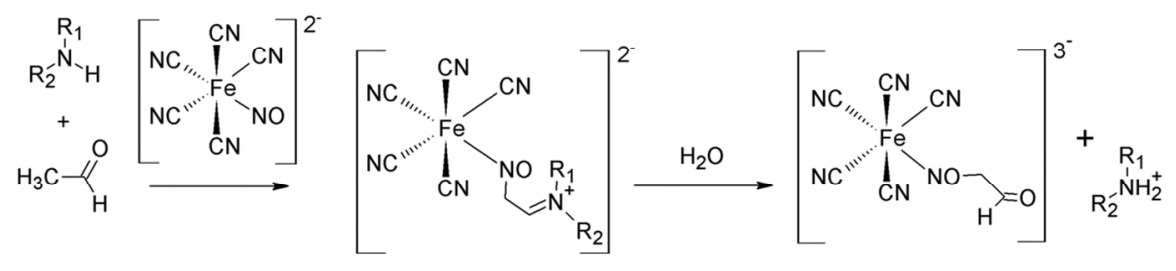

(b) Zimmerman

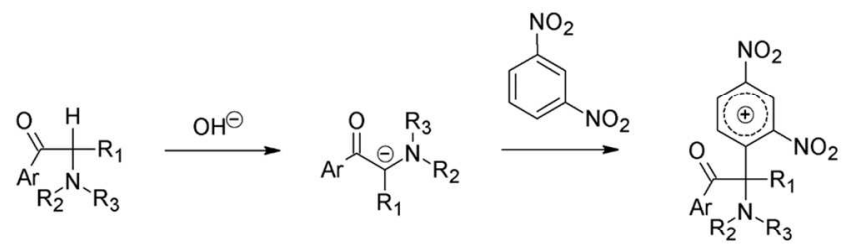

(c) Ferric Chloride

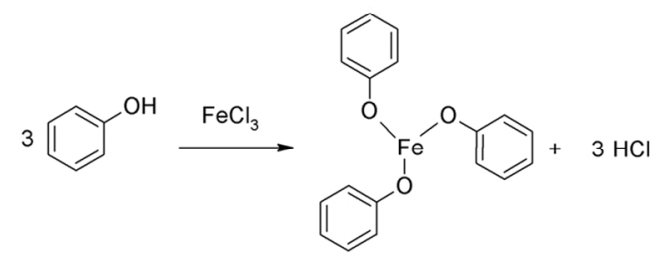

Figure 3. Chemical reactions of common color spot tests that are selective toward certain functional groups. Simon's reagent for secondary amines (a); Zimmerman reagent for $\beta$-amino ketones (b); and ferric chloride reagent for phenols (c).

$241 \times 200 \mathrm{~mm}(150 \times 150 \mathrm{DPI})$ 
(a) Duquenois-Levine

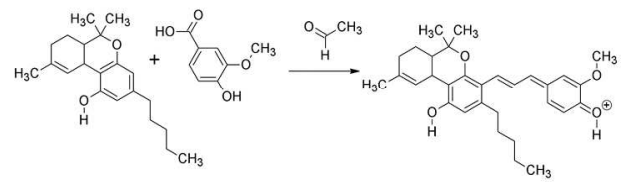

(c) Scott's

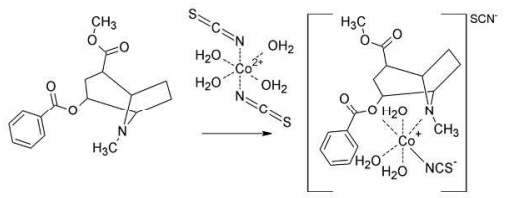

(e) Chen-Kao

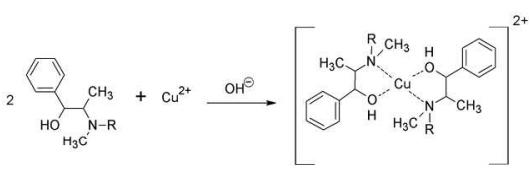

(g) Fast Blue BB

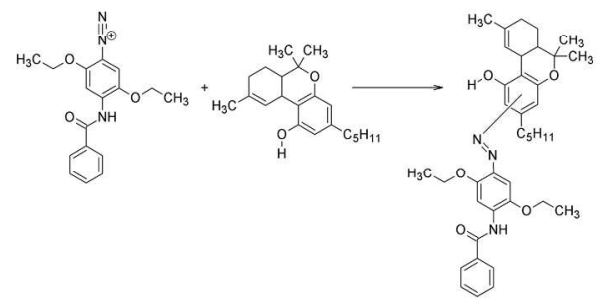

(b) Mecke

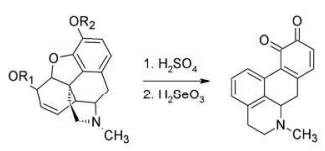

(d) Dille-Koppanyi

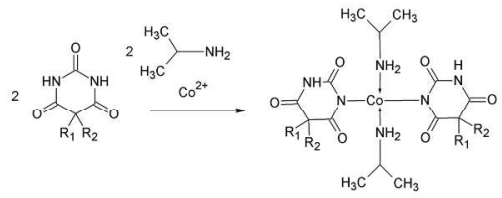

(f) Ehrlich's

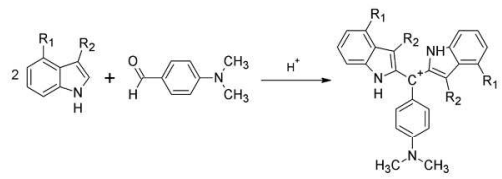

(h) Zwikker

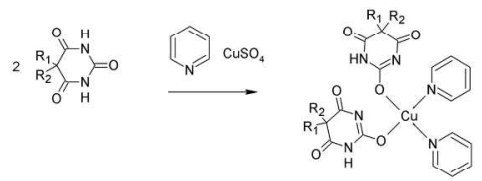

Figure 4. Chemical reactions of common color spot tests that are selective toward a drug class. DuquenoisLevine reagent for cannabinoids (a); Mecke reagent for opium alkaloids (b); Scott's reagent for cocaine (c); Dille-Koppanyi reagent for barbiturates (d); Chen-Kao reagent for ephedrine/norephedrine (e); Ehrlich's reagent for ergot alkaloids (and LSD) (f); Fast Blue BB reagent for cannabinoids (g); and Zwikker reagent for barbiturates $(h)$.

$411 \times 339 \mathrm{~mm}(150 \times 150 \mathrm{DPI})$ 


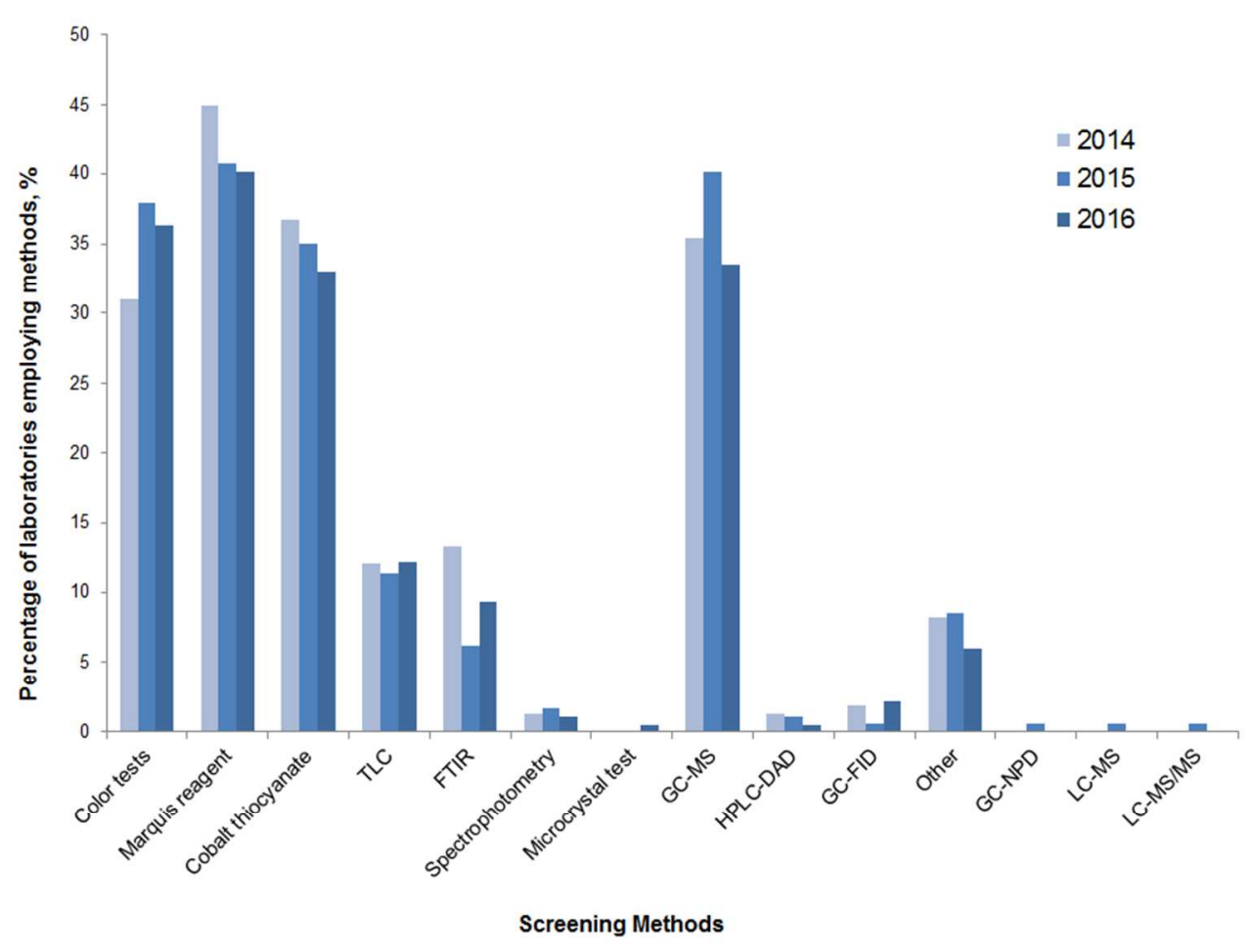

Figure 5. Screening methods performed by laboratories taking part in the UNODC's International Collaborative Exercises (ICE) study of seized materials over three separate studies from 2014-2016.

\section{$241 \times 174 \mathrm{~mm}(96 \times 96 \mathrm{DPI})$}


Table 1. Color test reagent compositions and targeted drugs for common color spot tests used in illicit drug detection.

\begin{tabular}{|c|c|c|c|}
\hline Test reagent & Composition & Targeted drugs & References \\
\hline Chen-Kao ${ }^{\text {a, b }}$ & $\begin{array}{l}\cdot \text { Acetic acid solution }(1 \% \mathrm{v} / \mathrm{v})(\mathbf{1}) \\
\cdot \text { Copper sulfate solution }(1 \% \mathrm{w} / \mathrm{v}) \\
\text { (2) } \\
\cdot \text { Sodium hydroxide solution }(8 \% \\
\text { w/v) (3) }\end{array}$ & $\begin{array}{l}\text { Ephedrine (and } \\
\text { norephedrine) }\end{array}$ & {$[26,29]$} \\
\hline $\begin{array}{l}\text { Dille- } \\
\text { Koppanyi }{ }^{\text {a, b, c, d }}\end{array}$ & $\begin{array}{l}\cdot 0.1 \mathrm{~g} \text { cobalt(II) acetate tetrahydrate } \\
\text { in } 100 \mathrm{~mL} \text { methanol with } 0.2 \mathrm{~mL} \\
\text { glacial acetic acid (1) } \\
.5 \mathrm{~mL} \text { isopropylamine in } 95 \mathrm{~mL} \\
\text { methanol (2) }\end{array}$ & Barbiturates & {$[26,30]$} \\
\hline $\begin{array}{l}\text { Duquenois- } \\
\text { Levine }^{a, b, c, d}\end{array}$ & $\begin{array}{l}\cdot 2.5 \mathrm{~mL} \text { acetaldehyde and } 2 \mathrm{~g} \\
\text { vanillin to } 100 \mathrm{~mL} \text { ethanol }(95 \% \\
\mathrm{v} / \mathrm{v})(\mathbf{1}) \\
\cdot \text { Conc. hydrochloric acid (2) } \\
\cdot \text { Chloroform (3) }\end{array}$ & $\begin{array}{l}\text { Cannabinoids in } \\
\text { cannabis }\end{array}$ & {$[26,30,31]$} \\
\hline Ehrlich's $^{\text {a, c }}$ & $\begin{array}{l}1 \mathrm{~g} p \text {-dimethylaminobenzaldehyde } \\
\text { in } 10 \mathrm{~mL} \text { methanol, then add } 10 \\
\mathrm{~mL} \text { conc. } o \text {-phosphoric acid (1) }\end{array}$ & $\begin{array}{l}\text { Ergot alkaloids and } \\
\text { LSD }\end{array}$ & [26] \\
\hline Fast Blue $B^{d}$ & $\begin{array}{l}\text { Fast Blue B salt (diazotized o- } \\
\text { dianisidine, } 1 \% \mathrm{w} / \mathrm{v})(\mathbf{1})\end{array}$ & $\begin{array}{l}\text { Cannabinoids in } \\
\text { cannabis }\end{array}$ & [32] \\
\hline Ferric chloride ${ }^{\text {a, b }}$ & $\begin{array}{l}8.25 \mathrm{~g} \text { ferric chloride hexahydrate } \\
\text { in } 100 \mathrm{~mL} \text { distilled water (1) }\end{array}$ & Phenols & โ30」 \\
\hline Froehde $^{a, b}$ & $\begin{array}{l}0.5 \mathrm{~g} \text { molybdic acid in } 100 \mathrm{~mL} \text { hot } \\
\text { conc. sulfuric acid (1) }\end{array}$ & $\begin{array}{l}\text { Range of aromatic } \\
\text { compounds }\end{array}$ & [33] \\
\hline Liebermann's ${ }^{\text {a, b }}$ & $\begin{array}{l}1 \mathrm{~g} \text { sodium/potassium nitrite in } 10 \\
\mathrm{~mL} \text { conc. sulfuric acid (1) }\end{array}$ & $\begin{array}{l}\text { Phenols and } \\
\text { substituted } \\
\text { benzene rings }\end{array}$ & {$[30,34,35]$} \\
\hline Mandelin's $^{\text {a, b }}$ & $\begin{array}{l}1 \mathrm{~g} \text { ammonium vanadate in } 1.5 \mathrm{~mL} \\
\text { water, diluted to } 100 \mathrm{~mL} \text { with } \\
\text { conc. sulfuric acid (1) }\end{array}$ & $\begin{array}{l}\text { Amphetamines and } \\
\text { anti-depressants }\end{array}$ & {$[26,30]$} \\
\hline Marquis ${ }^{a, b, c, d}$ & $\begin{array}{l}1 \mathrm{~mL} \text { formaldehyde }(40 \% \mathrm{v} / \mathrm{v}) \text { in } \\
100 \mathrm{~mL} \text { conc. sulfuric acid (1) }\end{array}$ & $\begin{array}{l}\text { Broad spectrum } \\
\text { test: mostly opium } \\
\text { alkaloids and }\end{array}$ & {$[26,30]$} \\
\hline
\end{tabular}




\begin{tabular}{|c|c|c|c|}
\hline & & amphetamines & \\
\hline Mecke $^{\mathrm{a}, \mathrm{b}}$ & $\begin{array}{l}1 \text { g selenious acid in } 100 \mathrm{~mL} \text { conc. } \\
\text { sulfuric acid (1) }\end{array}$ & Opium alkaloids & $\lfloor 26,30\rfloor$ \\
\hline Scott's ${ }^{a, b, d}$ & $\begin{array}{l}\text { Cobalt thiocyanate }(2 \% \mathrm{w} / \mathrm{v}) \\
\text { diluted 1:1 with glycerine (1) } \\
\text {. Conc. hydrochloric acid (2) } \\
\text { - Chloroform (3) }\end{array}$ & $\begin{array}{l}\text { Cocaine (and } \\
\text { methadone) }\end{array}$ & {$[26,30,36]$} \\
\hline Simon's ${ }^{b, c, d}$ & $\begin{array}{l}2 \mathrm{~mL} \text { acetaldehyde in } 100 \mathrm{~mL} \\
\text { sodium nitroprusside solution }(1 \% \\
\text { w/v) (1) } \\
\text { Sodium carbonate solution }(2 \% \\
\text { w/v) (2) }\end{array}$ & $\begin{array}{l}\text { Distinguishes } \\
\text { primary and } \\
\text { secondary amines }\end{array}$ & {$[26,30]$} \\
\hline Zimmerman $^{\mathrm{a}, \mathrm{b}, \mathrm{c},}$ & $\begin{array}{l}\cdot 2,4 \text {-dinitrobenzene }(1 \% \mathrm{w} / \mathrm{v}) \text { in } \\
\text { methanol (1) } \\
\cdot \text { Potassium hydroxide }(15 \% \mathrm{w} / \mathrm{v}) \\
\text { (2) }\end{array}$ & $\begin{array}{l}\text { Benzodiazepine } \\
\text { derivatives and } \\
\text { synthetic } \\
\text { cathinones }\end{array}$ & {$[26,37]$} \\
\hline Zwikker $^{\text {b,c,d }}$ & $\begin{array}{l}0.5 \mathrm{~g} \text { copper(II) sulfate } \\
\text { pentahydrate in } 100 \mathrm{~mL} \text { distilled } \\
\text { water (1) } \\
.5 \mathrm{~mL} \text { pyridine to } 95 \mathrm{~mL} \\
\text { chloroform (2) }\end{array}$ & Barbiturates & [33] \\
\hline
\end{tabular}

${ }^{a}$ contains corrosive chemicals

${ }^{\mathrm{b}}$ contains flammable chemicals

${ }^{c}$ contains toxic chemicals

${ }^{d}$ contains suspected/possible carcinogenic chemicals 
Table 2. Commercial companies producing color test kits for drugs of abuse and precursor material.

\begin{tabular}{|c|c|c|c|}
\hline Company & Test kits available & Target market & Reference \\
\hline $\begin{array}{l}\text { Sirchie } \\
\text { (NARK® tests) }\end{array}$ & $\begin{array}{l}27 \text { pouch tests } \\
21 \text { tube tests } \\
1 \text { drug wipe }\end{array}$ & Law enforcement & [68] \\
\hline $\begin{array}{l}\text { MMC } \\
\text { International BV } \\
\text { (Narcotic field } \\
\text { tests) }\end{array}$ & $\begin{array}{l}55 \text { tube tests } \\
3 \text { purity tests } \\
1 \text { spray } \\
1 \text { drug wipe } \\
1 \text { test strip }\end{array}$ & $\begin{array}{l}\text { Police, customs authorities and } \\
\text { forensic laboratories }\end{array}$ & [69] \\
\hline $\begin{array}{l}\text { NIK® Public } \\
\text { Safety } \\
\text { (NIK }{ }^{\circledR} \text { tests) }\end{array}$ & $\begin{array}{l}20 \text { pouch tests } \\
1 \text { tube test } \\
1 \text { drug wipe }\end{array}$ & Agencies & {$[70\rfloor$} \\
\hline $\begin{array}{l}\text { ODVTM Drug Tests } \\
\text { (NarcoTest and } \\
\text { NarcoPouch) }\end{array}$ & $\begin{array}{l}20 \text { pouch tests } \\
2 \text { tube tests }\end{array}$ & Investigators & {$[71]$} \\
\hline $\begin{array}{l}\text { IDenta } \\
\text { Touch\&Know }\end{array}$ & 26 test kits & $\begin{array}{l}\text { Retail-consumer market and law } \\
\text { enforcement }\end{array}$ & {$[72]$} \\
\hline TestKitPlus & $\begin{array}{l}5 \text { Reagent dropper } \\
\text { bottles } \\
3 \text { tube tests }\end{array}$ & $\begin{array}{l}\text { Medical centers, harm reduction } \\
\text { organizations, government } \\
\text { agencies and individuals }\end{array}$ & [73] \\
\hline EZ Test & $\begin{array}{l}13 \text { test kits } \\
2 \text { purity tests }\end{array}$ & Professionals and individuals & [74] \\
\hline $\begin{array}{l}\text { Lynn Peavey } \\
\text { Company } \\
\text { (QuickCheck) }\end{array}$ & $\begin{array}{l}6 \text { tube tests } \\
6 \text { test pouches }\end{array}$ & Law enforcement and laboratories & {$[75]$} \\
\hline
\end{tabular}

